\title{
Structural framework of digital transformation enablers towards enhancing the social media marketing
}

\author{
Sania Khan ${ }^{a^{*}}$
}

${ }^{a}$ College of Business Administration, Prince Sattam Bin Abdulaziz University, Al Kharj, Saudi Arabia

\section{H R O N I C L E}

\section{Article history:}

Received: June 20, 2020

Received in revised format:

August 302020

Accepted: September 18, 2020

Available online:

September 23, 2020

Keywords:

Digitalization

Social Media Marketing

Digital Marketing

Digital Transformation

Interpretive Structural Modeling

Delphi Technique

\section{A B S T R A C T}

Most of the organizations today look forward to streamlining their business with the rapid needs of the society. However, they do not consider the holistic view of various digital driving factors. The paper aimed to develop a structural framework using the enablers of Digital Transformation (DT) by applying qualitative and rational approaches to develop a conceptual model of DT adoption for various industries. The assimilated approach of Delphi and Interpretive Structural Modelling demonstrated the qualitative data-driven theoretical structure by identifying fourteen enablers of DT and developed a logical model in nine levels. The driving and dependency powers of each enabler were portrayed in MIC MAC analysis. The government regulation and market pressure found as key drivers with strong driving and low dependency powers occupying the lowest level which influences customer demand, behavior and expectations and process, performance improvement of the business. The model demonstrates a deep understanding of global firms to leverage various dimensions while taking transformation decisions in their business process and gain a competitive edge. Further, any organization that looks for adopting digital transformation can consider these factors or models in deciding the implementation process. It recommends researchers to validate the model or may prioritize the factors and sub-factors for multi-criterion based decision making process for unique findings.

\section{Introduction}

Mobile Phones and internet technologies have considerably affected every segment of the market economy. The pervasiveness of modern technology has become an enduring driver for business innovation which propitious the firms with digital transformation (DT). For the last two decades, technology has brought tremendous changes in the way how organizations are leading their business to gain and serve more customers and improve their customer experience. In this technological evolutionary phase, the leading business pioneers like Facebook, eBay, Amazon, Uber, Google, and so on embraced new technologies and shown they have reinforced their customers and company sales volume. Similarly, many recent research studies noticed an incremental sales volume of $5 \%$ by facilitating their customers with online and other technological tools (Malcolm, 2015). Smartphones and other internet technologies like artificial intelligence, Blockchain, cloud connection, Internet of Things (IoT) have amplified reality and virtual reality-based approaches in the global market. Subsequently, this approach has been stimulating a greater presence in the broader economy, improving efficiency by supplementing other production factors and foster advancements by intensely reducing operational costs. Karen et al. (2018) in their study stated digitalization is reinforcing digital technology in shaping the socio-technical structure, which is referred to as product or services, user and customer experience, human interactions, business process, and norms. Though the phenomenon of Digitalization, Digital Innovation, and DT are used interchangeably, digital innovation is the source for concept building and digitalization is the outcome (Fichman et al., 2014). Further, Karen et al. (2018) extended digital innovation, and digitalization facilitates the * Corresponding author.

E-mail address: sa.khan@psau.edu.sa (S. Khan) 
major changes in the business process and results in the DT of firms and industries. The extant literature provides evidence in investigating the DT from the organization's point of view (Karen et al., 2018; Kannan \& Hongshuang, 2017). Most recent studies noticed the DT is booming in the modern business and generating new business avenue, understanding, and identifying the means of communication with their customers with the help of the digital platform. Based on this, the industrial experts are developing new business models to implement in their business fields with the hope to serve their customers better and create a difference in the market with a deep insight into customer and user experience. This motivated the author to explore more on DT and which factors logically prove to be the driving (DRP) factors for the firms. Though the attempts were limited in answering a few research questions such as the reasons why firms undergo DT, how do they accomplish, how firms are affected by DT, instant and future goals of a firm and their consequences after the execution of DT. There exists a research gap in understanding what are the most essential determinants that are driving organizations towards DT and how logically the firms are planning strategically to survive themselves in the digitally transformed market. The study provides some clear inferences to the firms, on which enablers need to emphasize. So, the problem statement of this study holds in addressing the below three research questions:

- RQ1: What are the most important driving factors for organizations towards market DT

- RQ2: What are the levels of driving powers for each identified factor.

- RQ3: What are the contextual inter-relationships of each variable.

- RQ4: How digitalization will help in augmenting the social media marketing.

The literature shows that DT and IT adoption practices have been deliberated from various levels by diverse underlying theories, by which the research on DT enablers can be considered as novel and intricate. So, a qualitative research approach is imperative to inspect complex collaborations between corporations, technologies, and customers. In the view of today's global market arena, there are a lot of disagreements and debates on whether the radical changes in digital innovation are the driving factors of market DT or they stand in the way of digital disruption (Skog et al., 2018; Kane et al., 2015). Therefore, the Delphi study as a qualitative approach used to determine the consensus and the extent to which the industrial experts agree with the identified factors as enablers for DT. Therefore, the central objective of this paper is to develop a structural framework of digital transformation with the identified elements of emerging digital innovation, and this is pursued in two folds. Therefore, the study is organized firstly by identifying the most driving DT factors for its adoption through a retrospective literature review. Secondly, the qualitative integrated method of Delphi's study and Interpretive Structural Modelling (ISM) were applied to understand the conceptual relationship among the identified elements. ISM is a popular and well established strategic method for recognizing associations among different variables in a complex system (Warfield, 1974 and Sage, 1977). ISM is also used by numerous researchers in the field of business, engineering, and social sciences. The study presents the in detail stepwise development of the model further explaining the findings and discussing followed by conclusions and future research directions.

\section{Literature Review}

In the recent years, the use of intimate themes like agile practices, cloud computing, the Internet of Things (IoT), blockchain technology, chatbots, Artificial Intelligence (AI) and so on by the leading firms are stimulating the industry even with a more aggressive approach to DT to survive and compete with others. The companies are suffering from low margins and high competition, subsequently hindering them with low market standards and with no security in competitive advantage. So, organizations to incorporate the latest technological developments and trends accordingly with the digital shifts happening at least in a similar industry they do business to influence the market opportunities and overcome market pressure (Hartl \& Hess, 2017; Berghaus \& Back, 2017). The enablers of DT are exclusively different from other technologies. However, they play a prominent role in the production, service, and external issues of the firm. Hence, this study reviewed the extant literature which is most recent and appropriate to DT expecting some latest updates from industry experts from their interviews, case analysis, and in-depth studies conducted by previous studies. Most of the studies are relevant to manufacturing, automotive, banking, and other general business industries. Our study attempted to collect all the possible drivers of DT from the literature and will involve the industrial experts in Delphi study to validate their appropriateness in the generalization of any business process. Every time the customer comes across a better digital experience, they expect new heights next time. Since the customers are paying for their desired quality and flexible services, their demands, expectations, and behavior are triggering the organizations to shift for a digital transformation (Haffke et al., 2017; Schmidt et al., 2017; Isaksson, \& Hylving, 2017; Mihailescu et al., 2015; Kirsten et al., 2018; Karen et al., 2018). Remane et al. (2016); Berghaus and Back (2017) and Kirsten et al. (2018) in their studies noticed that the government enforces the organizations with new regulatory changes to adhere to environmental protection and sustainability standards. Changing competitive landscape is another driving factor that indicates the companies need to take action to start DT because of the forthcoming threat from existing and new competitors. This feature can allow companies to bring innovative ideas in product development and integrates both digital and physical channels (Karen et al., 2018; Bilgeri et al., 2017; Fichman et al., 2014; Mihailescu et al., 2015; Berghaus \& Back, 2017). Kirsten et al., 2018 conducted a case analysis and asserted a few companies state "limiting existing structures" as their important driver to implement DT, which indicates they possess limited IT infrastructures and capabilities with an inability to impulsively respond to technological changes or instrumentalize the modern technology. Today most of the corporate decisions are driven by cost features. The firms look at a high Return on Investment (ROI) to determine the performance of DT. Berghaus 
and Back (2017) argued the DT advances business and production processes alongside better operational performance and helps in reducing the breakdowns and transition time leading a comparative cost reduction. Kirsten et al. (2018) in their study identified twelve driving factors which are further sub-categorized under three main groups viz., organizational, external, and individual factors. Further to explain the cause and effect relationship, these factors are further conveyed under pre-conditions (innovation push, management support, market pressure, government regulation, and employee support), while expected outcomes (process and workplace improvement) and the rest (vertical \& horizontal integration, cost reduction, customer demand, supply chain) fall under either group. The study identified that external factors are the most vital issues that demand the firms for DT. Innovation push and market pressure are the essential enablers which are imposing organization to act accordingly and supply chain enhances the innovation process as it serves as a connection between suppliers, customers, and invention. Ezeokoli et al. (2016) argued, many studies expressed DT drivers as income growth, improved business agility, customer satisfaction, better operational proficiency, convenience, and better-quality technical standard, improved employee productivity, and competitive advantage. Morakanyane et al. (2017) allude that both research and practices of DT do not have one combined central interpretation. While few authors connect DT with business models and strategy, the other interprets it as a shift in paradigm (Berman 2012; Berman \& Marshall 2014). Morakanyane et al. (2017) in conceptualizing the DT in business organizations, the authors identified five key drivers viz., digital technologies, digital capabilities, strategies, business models and value chain, which were also articulated repeatedly by multiple previous studies. To provide a more comprehensive understanding the author defined "digital technology" as the new and emerging technologies that can be used in business. "Digital capabilities" are the technical competencies that are essential by employees, customers, and stakeholders who can drive the firms to flourish in the digital atmosphere. Kane et al. (2015a) demonstrated just using digital technologies to push DT are not sufficient, but also it must use digital capabilities, strategies, talent development, and culture. Nwankpa and Roumani (2016) also found that DT is positively associated with overall performance in terms of profitability, customer retention, increase in sales, and good ROI when compared to the organizations which are lacking in digitalizing their business. Though most of the driving factors of DT were interchangeably referred by many studies, this study identified and listed the below DT drivers by avoiding the repetition of those factors and presents their definition and article references as demonstrated in Table 1.

Table 1

Identified factors from the review of literature

\begin{tabular}{|c|c|c|c|}
\hline S. No & Drivers & Definition & Article References \\
\hline 1 & $\begin{array}{l}\text { Customer Demand, } \\
\text { Behavior, and Expec- } \\
\text { tations (CDBE) }\end{array}$ & $\begin{array}{l}\text { The dynamic behavior of customers with ever time changing needs } \\
\text { and looking for something better than what they have already expe- } \\
\text { rienced. }\end{array}$ & $\begin{array}{l}\text { Karen et al., 2018; Hartl \& Hess, 2017; } \\
\text { Isaksson, V., \& Hylving, L. (2017); } \\
\text { Mihailescu, M. et al., 2015; Kirsten et al., } \\
\text { 2018; Berman (2012) }\end{array}$ \\
\hline 2 & $\begin{array}{l}\text { Changing Competitive } \\
\text { Landscape (CCL) }\end{array}$ & $\begin{array}{l}\text { It is the business analysis which identifies competitors and under- } \\
\text { standing their core values, mission, vision strengths and weak- } \\
\text { nesses }\end{array}$ & $\begin{array}{l}\text { Karen et al., 2018; Bilgeri, D. et al., 2017; } \\
\text { Fichman et al., 2014; Mihailescu et al., } \\
\text { 2015; Berghaus \& Back, 2017; Mo- } \\
\text { rakanyane et al., } 2017\end{array}$ \\
\hline 3 & $\begin{array}{l}\text { Vertical \& Horizontal } \\
\text { Integration (VHI) }\end{array}$ & $\begin{array}{l}\text { Vertical integration is internal linking among different fragments } \\
\text { of the company and making the facilities associated with the data- } \\
\text { base. Horizontal integration is IT systems used at various phases in } \\
\text { the business process including information and material exchange } \\
\text { within a company and its value network outside. }\end{array}$ & Kirsten et al., 2018, Ezeokoli et al., 2016 \\
\hline 4 & Business Model (BM) & $\begin{array}{l}\text { Various capacities in the organization are supposed to transform } \\
\text { because of the digital transformation process with value creation. }\end{array}$ & Berman \& Marshall (2014); Berman (2012) \\
\hline 5 & $\begin{array}{l}\text { Process \& Perfor- } \\
\text { mance Improvement } \\
(\mathrm{PPI})\end{array}$ & $\begin{array}{l}\text { The need to enhance the quality and output by saving time and in- } \\
\text { corporating flexibility in business dealings and production. }\end{array}$ & $\begin{array}{l}\text { Nwankpa \& Roumani 2016; Kirsten et al., } \\
\text { 2018; Ezeokoli et al., 2016; Morakanyane } \\
\text { R. et al., } 2017\end{array}$ \\
\hline 6 & $\begin{array}{l}\text { Workplace Improve- } \\
\text { ment (WI) }\end{array}$ & $\begin{array}{l}\text { Improving the working methods and ergonomics by involving ro- } \\
\text { bots for complex tasks. }\end{array}$ & $\begin{array}{l}\text { Nwankpa \& Roumani 2016; Kirsten et al., } \\
\text { 2018; Ezeokoli et al., } 2016\end{array}$ \\
\hline 7 & $\begin{array}{l}\text { Cost Reduction \& } \\
\text { Revenue Growth } \\
\text { (CRRG) }\end{array}$ & It is offering high-quality services relatively at a low cost. & $\begin{array}{l}\text { Nwankpa \& Roumani 2016; Kirsten et al., } \\
\text { 2018; Ezeokoli et al., } 2016\end{array}$ \\
\hline 8 & Supply Chain (SC) & $\begin{array}{l}\text { Planning and execution of daily operations between the company, } \\
\text { customers, and suppliers. }\end{array}$ & Kirsten et al., 2018 \\
\hline 9 & $\begin{array}{l}\text { Digital Technologies } \\
\text { Innovation (DTI) }\end{array}$ & $\begin{array}{l}\text { It is the pre-requisite to drive the firm towards digitalization by } \\
\text { considering its value and importance in the competitive world with } \\
\text { the emerging technologies. It also integrates digital technology to } \\
\text { change the business process innovatively. }\end{array}$ & $\begin{array}{l}\text { Nwankpa \& Roumani 2016; Kirsten et al., } \\
\text { 2018; Morakanyane R. et al., 2017; Karen } \\
\text { et al., 2018; Mihailescu, M. et al., 2015; } \\
\text { Kane et al., } 2015\end{array}$ \\
\hline 10 & $\begin{array}{l}\text { Management Support } \\
\text { (MS) }\end{array}$ & $\begin{array}{l}\text { The key support from high-level consultants in the decision-mak- } \\
\text { ing process for the acceptance and changing the business process. }\end{array}$ & Kirsten et al., 2018 \\
\hline 11 & $\begin{array}{l}\text { Digital Capabilities } \\
\text { (DC) }\end{array}$ & $\begin{array}{l}\text { The skills required by employees, customers, and stakeholders by } \\
\text { subordinating in the pre-adoption phase and majorly involving } \\
\text { them at operational and usage levels to bring a radical change in } \\
\text { the digital setting of the organization over time. }\end{array}$ & $\begin{array}{l}\text { Kirsten et al., 2018; Morakanyane et al., } \\
2017\end{array}$ \\
\hline 12 & $\begin{array}{l}\text { Government Regula- } \\
\text { tions (GR) }\end{array}$ & $\begin{array}{l}\text { The imposition of rules on organizations to go for technological } \\
\text { use for maintaining ecological and sustainable standards. }\end{array}$ & $\begin{array}{l}\text { Karen et al., 2018; Remane et al., 2016; } \\
\text { Mihailescu, M. et al., } 2015\end{array}$ \\
\hline 13 & Market Pressure (MP) & $\begin{array}{l}\text { It is the stress among multiple players to gain market share and be } \\
\text { competitive. }\end{array}$ & Kirsten et al., 2018 \\
\hline 14 & $\begin{array}{l}\text { Strategy \& Value } \\
\text { Creation (SVC) }\end{array}$ & $\begin{array}{l}\text { Framing Policies and identifying benefits at an organization-wide } \\
\text { as an outcome of digital transformation. }\end{array}$ & $\begin{array}{l}\text { Morakanyane et al., 2017; Berman 2012; } \\
\text { Berman \& Marshall (2014) }\end{array}$ \\
\hline
\end{tabular}




\section{Integrated Approach of Delphi Technique and Interpretive Structural Modeling (ISM)}

\subsection{Interpretive Structural modeling}

Under some circumstances, there exists a huge number of elements and interactions among those elements that often create difficulties for individuals and groups in dealing with such complex issues. This happens due to the presence of direct and indirect relationships among these elements and may intricate the structure of the whole system. Therefore, Interpretive Structural Modelling (ISM) is imperative in transforming uncertain and poorly expressed system models into structured visible models logically. Warfield in 1974 was the first who proposed this method. Most of the researchers consider ISM as an interactive learning process by well defining the complex relationships into comprehensive systematic models portraying into words and graphics (Sage, 1977; Warfield, 1974). ISM provides insight through a collective understanding of various relationships. ISM is typically conducted in 8 steps starting with the identification of variables connected to a subject or a problem. Then it chooses a contextual relation among variables and develops a structural self-interaction matrix (SSIM) by using a pairwise comparison of variables. Further SSIM is converted into a reachability matrix (RM) with its transitivity checked. After completing the transitivity embedding a matrix model is derived. Then level-wise partitioning of elements is done and an ISM based structural model is extracted. The procedure in Fig. 1 demonstrates the stepwise stages of the ISM process.

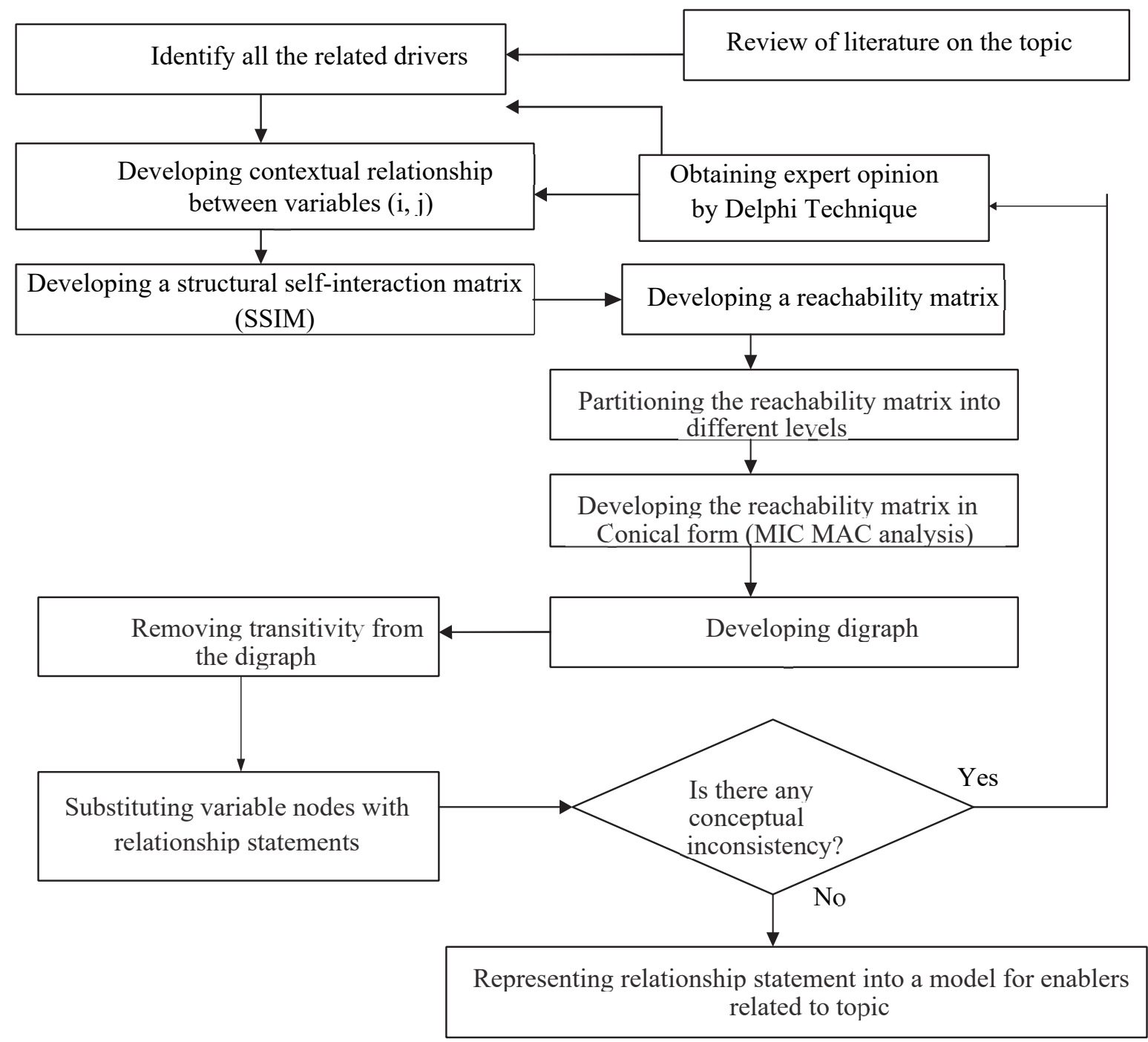

Fig. 1. Flow chart for developing ISM model

\subsection{Steps Involved in ISM Methodology}

Warfield 1974 has applied some fundamental ideas of graph theory and Boolean algebra so that when executed, the manmachine interactive model, conceptual, theoretic and computational influence is subjugated in constructing a directed graph (digraph). 
Step 1: Identification of the elements relevant an issue - This step is already accomplished previously in the literature review section, where 14 driving factors for DT were identified.

Step 2: Establish a contextual relationship between elements and

Step 3: Develop a structural self-interaction matrix (SSIM)

The above steps 2 and 3 together accomplished with the help of the Delphi technique which is explained below.

Data Collection using Delphi Technique

Delphi method is a scientific and organized way of forecasting that involves controlled interaction among some panel experts on a subject developed by Rand Corporation. For the reason to answer the research questions and to validate the identified driving factors relevant to DT, it is essential to gain an understanding of the mutual experience of industry experts. Therefore, the Delphi method is considered to be the most appropriate, as it depends on agreement on a specific question through a structured process of an iterative questionnaire with an organized response. Over many years Delphi method is seen eminently effective in comparison to other research methods, as it is more strategic approach in developing an active communication procedure with experts by continuous feedback avoiding the confrontation which possibly may lead to biases (Okoli \& Pawlowski 2004; Skinner et al., 2015). In this case, the primary qualitative data were collected using the Delphi technique, and then the contextual relationships were developed to establish the SSIM. In other words, both steps 2 and 3 jointly accomplished using the Delphi study. For selection of panel members being a very crucial part of this method, proper care was taken in choosing the experts for the study. Therefore, 18 potential experts who are interested to share their views were selected in an exclusive international business conference on DT conducted in Riyadh, Saudi Arabia. These participants are from across the world who are designated in senior positions in handling consultation projects, CTOs, members of digitalization initiatives, and experts involved in developing business models, head of IT, special projects director. Table 2 demonstrates the profile of the Delphi panel experts in this study.

Table 2

Profile of Delphi Panel Experts

\begin{tabular}{lcc}
\hline Industrial Panel Experts Profile & Frequency & Industry Sector \\
\hline Consultant & 2 & Banking \& Finance \\
Digital Transformation Director & 3 & Automotive \\
Chief Technology Officer & 2 & Media \\
Business Intelligence Head & 3 & Telecommunication \\
Digital Marketing Head & 2 & Food Industry \\
Special Project Director & 3 & Manufacturing \& Furniture \\
Data Analytics Director & 1 & FMCG \\
Head Ecommerce & 2 & Retailers \\
\hline
\end{tabular}

The data collection was conducted in three rounds by the moderator to get the majority of consensus on the relationships. The first round of questionnaire distribution was done on the conference day, while the subsequent rounds of data collection were done by contacting experts through emails. The survey questionnaire was circulated among all the 18 experts, where they were asked to enter their opinion by conducting a pairwise comparison among the set of variables $i$ and $j$ as per the instructions provided. This data collection using the Delphi method accomplishes the first two stages of ISM model development namely establishing the contextual relationship and structural self-interaction matrix (SSIM) to decide the dominant or driving factors of DT and also to obtain the structural relationship existing among all the enablers. The influencing type of relationship "leads to" under intent structure proposed by Warfield (1974) was followed. The contextual relationship among the pairs of identified drivers are sought as follows"

$$
\text { Element (i) enables Element }(\mathrm{j}) \ldots \ldots \ldots \text { For } \mathrm{i}, \mathrm{j}=1,2,3 \ldots \ldots .14 \text { and } \mathrm{i} \neq \mathrm{j}
$$

The relationship mapped for each pair of an element are entered into a triangular matrix using the following relationship codes.

$$
\begin{gathered}
\mathrm{V}=\text { variable (i) enables (j) but variable (j) is do not enable element (i) } \rightarrow \text { one way relationship. } \\
\mathrm{A}=\text { variable (j) enable (i) but variable (i) is do not enable variable (j) } \rightarrow \text { one way relationship. } \\
\mathrm{X}=\text { both variable (i) and variable (j) enable each other } \rightarrow \text { a two way relationship } \\
\mathrm{O}=\text { both variable (i) and variable (j) does not enable each other } \rightarrow \text { no relationship }
\end{gathered}
$$

Since a total of 14 driving factors were identified for the model development, there exist 91 pairs [14 (14-1)/2] of contextual relationships. To develop a rationale ISM, a multi-round Delphi opinion survey was conducted using V, A, X, O codes. In the first round, 8 experts have a similar consensus and the rest 9 have different opinions. Again the modified questionnaire with the aggregated consensus in the first round was circulated to all the experts. This second round resulted in 11 similar opinions and also resulted in a conflict of responses due to near tie. As there were already the majority of consensus, the questionnaire with an aggregated opinion was again circulated for the last round to check if any expert would like to change their decision on the relationship of the elements. Though there was a lot of conflict of responses that existed during the first two rounds the final round has got 13 consensuses and the iterative process was stopped here as the survey has got a majority of consensus. 
The summarized opinions were represented in the final structural self-interaction matrix (SSIM) after Delphi Round-3 as shown in Table 3.

Table 3

Final Structural Self-Interaction Matrix after Delphi Round - 3

\begin{tabular}{|c|c|c|c|c|c|c|c|c|c|c|c|c|c|c|}
\hline Enabler & $\mathbf{j}$ & $\sum_{\infty}^{u}$ & $\hat{\Sigma}$ & 药 & U & $\sum^{\infty}$ & 量 & U & $\begin{array}{l}\text { U } \\
\text { v }\end{array}$ & $\sum$ & $\bar{a}$ & $\sum_{\infty}$ & $\bar{\nabla}$ & ن \\
\hline i & & 14 & 13 & 12 & 11 & 10 & 9 & 8 & 7 & 6 & 5 & 4 & 3 & 2 \\
\hline CDBE & 1 & $\mathrm{X}$ & $\mathrm{X}$ & $\mathrm{X}$ & $\mathrm{X}$ & $\mathrm{X}$ & $X$ & $\mathrm{X}$ & $\mathrm{X}$ & $X$ & $\mathrm{X}$ & $\mathrm{A}$ & $X$ & $\mathrm{X}$ \\
\hline CCL & 2 & $X$ & A & $\mathrm{O}$ & $X$ & $\mathrm{X}$ & $X$ & $\mathrm{~V}$ & $\mathrm{~V}$ & V & $\mathrm{X}$ & $\mathrm{V}$ & V & \\
\hline VHI & 3 & $\mathrm{X}$ & A & A & $\mathrm{A}$ & $X$ & A & $\mathrm{V}$ & V & V & $\mathrm{X}$ & A & & \\
\hline BM & 4 & $\mathrm{~V}$ & A & A & A & $\mathrm{X}$ & A & $\mathrm{V}$ & $\mathrm{V}$ & $\mathrm{V}$ & $\mathrm{V}$ & & & \\
\hline PPI & 5 & A & A & $\mathrm{O}$ & A & $\mathrm{X}$ & A & $\mathrm{X}$ & $\mathrm{X}$ & A & & & & \\
\hline WI & 6 & A & $\mathrm{O}$ & $\mathrm{O}$ & A & A & A & A & A & & & & & \\
\hline CRRG & 7 & A & $\mathrm{O}$ & $\mathrm{O}$ & A & A & A & A & & & & & & \\
\hline SC & 8 & A & A & A & A & A & A & & & & & & & \\
\hline DTI & 9 & V & A & A & $\mathrm{X}$ & X & & & & & & & & \\
\hline MS & 10 & $\mathrm{~V}$ & A & A & $\mathrm{X}$ & & & & & & & & & \\
\hline DC & 11 & $X$ & A & A & & & & & & & & & & \\
\hline GR & 12 & V & $\mathrm{X}$ & & & & & & & & & & & \\
\hline MP & 13 & V & & & & & & & & & & & & \\
\hline SVC & 14 & & & & & & & & & & & & & \\
\hline
\end{tabular}

Step 4: Establishing a Reachability Matrix after incorporating Transitivity - This step involves transforming the above SSIM into the reachability matrix (RM) by substituting V, A, X, O by 1 , and 0 as per the case. The substitution is based on the following rules:

If $(i, j)$ in SSIM is $V$, then ( $i, j)$ in RM becomes 1 and $(j, i)$ noted as 0

If $(i, j)$ in SSIM is $A$, then $(i, j)$ in RM becomes 0 and $(j, i)$ noted as 1

If $(i, j)$ in SSIM is $X$, then $(i, j)$ in RM becomes 1 and $(j, i)$ noted as 1

If $(i, j)$ in SSIM is $O$, then $(i, j)$ in RM becomes 0 and $(j, i)$ noted as 0

The final RM is derived by multiplying the initial RM by itself until it attains the state of transitivity. This process also tests the transitivity condition which represents the rising power of the initial RM successively will lead two sequential matrices until they become identical. The transitivity concept is introduced to address the possible gaps in ideas during SSIM development. Consequently, the driving power (DRP) and the dependence power (DEP) of each variable is derived by considering sum of all 1's in the row for the former and the sum of all 1's in columns for the latter as demonstrated in Table 4.

Table 4

Development of Reachability Matrix (RM) to find DRP and DEP

\begin{tabular}{|c|c|c|c|c|c|c|c|c|c|c|c|c|c|c|c|c|}
\hline Enabler & $\mathrm{j}$ & $\stackrel{\circlearrowright}{\infty}$ & $\sum$ & $\frac{\alpha}{\sigma}$ & $\circlearrowright$ & $\sum^{\infty}$ & $\ddot{\rho}$ & $\underset{\sim}{\cup}$ & $\begin{array}{l}\mho \\
\text { ㅁ } \\
\mho\end{array}$ & 3 & $\bar{a}$ & $\sum_{m}$ & $\underset{P}{>}$ & $\circlearrowright$ & $\stackrel{\underline{m}}{\Theta}$ & $\frac{\hat{\alpha}}{\hat{\alpha}}$ \\
\hline$\nabla \quad \mathrm{i}$ & & 14 & 13 & 12 & 11 & 10 & 9 & 8 & 7 & 6 & 5 & 4 & 3 & 2 & 1 & \\
\hline CDBE & 1 & 1 & 1 & 1 & 1 & 1 & 1 & 1 & 1 & 1 & 1 & 0 & 1 & 1 & 1 & 13 \\
\hline CCL & 2 & 1 & 0 & 0 & 1 & 1 & 1 & 1 & 1 & 1 & 1 & 1 & 1 & 1 & 1 & 12 \\
\hline VHI & 3 & 1 & 0 & 0 & 0 & 1 & 0 & 1 & 1 & 1 & 1 & 0 & 1 & 0 & 1 & 8 \\
\hline BM & 4 & 1 & 0 & 0 & 0 & 1 & 0 & 1 & 1 & 1 & 1 & 1 & 1 & 0 & 1 & 9 \\
\hline PPI & 5 & 0 & 0 & 0 & 0 & 1 & 0 & 1 & 1 & 0 & 1 & 0 & 1 & 1 & 1 & 7 \\
\hline WI & 6 & 0 & 0 & 0 & 0 & 0 & 0 & 0 & 0 & 1 & 1 & 0 & 0 & 0 & 1 & 3 \\
\hline CRRG & 7 & 0 & 0 & 0 & 0 & 0 & 0 & 0 & 1 & 1 & 1 & 0 & 0 & 0 & 1 & 4 \\
\hline $\mathrm{SC}$ & 8 & 0 & 0 & 0 & 0 & 0 & 0 & 1 & 1 & 1 & 1 & 0 & 0 & 0 & 1 & 5 \\
\hline DTI & 9 & 1 & 0 & 0 & 1 & 1 & 1 & 1 & 1 & 1 & 1 & 1 & 1 & 1 & 1 & 12 \\
\hline MS & 10 & 1 & 0 & 0 & 1 & 1 & 1 & 1 & 1 & 1 & 1 & 1 & 1 & 1 & 1 & 12 \\
\hline DC & 11 & 1 & 0 & 0 & 1 & 1 & 1 & 1 & 1 & 1 & 1 & 1 & 1 & 1 & 1 & 12 \\
\hline GR & 12 & 1 & 1 & 1 & 1 & 1 & 1 & 1 & 0 & 0 & 0 & 1 & 1 & 0 & 1 & 10 \\
\hline MP & 13 & 1 & 1 & 1 & 1 & 1 & 1 & 1 & 0 & 0 & 1 & 1 & 1 & 1 & 1 & 12 \\
\hline SVC & 14 & 1 & 0 & 0 & 1 & 0 & 0 & 1 & 1 & 1 & 1 & 0 & 1 & 1 & 1 & 9 \\
\hline DEP & & 10 & 3 & 3 & 8 & 10 & 7 & 12 & 11 & 11 & 13 & 7 & 11 & 8 & 14 & 126 \\
\hline
\end{tabular}

Step 5: Level partitioning - This step involves deriving reachability and antecedent sets for each variable from Table 3 . Reachability set contains the variable itself and all other variables in its row with 1's and the antecedent set contains the variable itself and all other variables in its column with 1's. The common elements from these two sets fall under the category of the intersection set. The element for which the reachability and intersection sets are the same will occupy top-level in ISM hierarchy and this top-level element does not promote any other element to achieve above its level. After identifying the top- 
level element, it is successively disconnected from other elements. This process is repeated till identifying the levels of other variables as shown in tables 5 to 13 respectively. After the subsequent iterations, the consolidated table 14 below represents the levels occupied by each of the elements.

Table 5

Level partitioning Iteration 1

\begin{tabular}{clll}
\hline Enabler & \multicolumn{1}{c}{ Reachability Set } & \multicolumn{1}{c}{ Antecedent Set } & Intersection \\
\hline CDBE & $1,2,3,5,8,9,10,11,12,13,14$ & $1,2,3,4,5,6,7,8,9,10,11,12,13,14$ & $1,2,3,5,8,9,10,11,12,13,14$ \\
CCL & $1,2,3,4,5,6,7,8,9,10,11,14$ & $1,2,5,9,10,11,13,14$ & $1,2,5,9,10,11,14$ \\
VHI & $1,3,5,6,7,8,10,14$ & $1,2,3,4,5,9,10,11,12,13,14$ & $1,3,5,10,14$ \\
BM & $1,3,4,5,6,7,8,10,14$ & $2,4,9,10,11,12,13$ & 4,10 \\
PPI & $1,2,3,5,7,8,10$ & $1,2,3,4,5,6,7,8,9,10,11,13,14$ & $1,2,3,5,7,8,10$ \\
WI & $1,5,6$ & $1,2,3,4,6,7,8,9,10,11,14$ & 1,6 \\
CRRG & $1,5,6,7$ & $1,2,3,4,5,7,8,9,10,11,14$ & $1,5,7$ \\
SC & $1,5,6,7,8$ & $1,2,3,4,5,8,9,10,11,12,13,14$ & $1,5,8$ \\
DTI & $1,2,3,4,5,6,7,8,9,10,11,14$ & $1,2,9,10,11,12,13$ & $1,2,9,10,11$ \\
MS & $1,2,3,4,5,6,7,8,9,10,11,14$ & $1,2,3,4,5,9,10,11,12,13$ & $1,2,3,4,5,9,10,11$ \\
DC & $1,2,3,4,5,6,7,8,9,10,11,14$ & $1,2,9,10,11,12,13,14$ & $1,2,9,10,11,14$ \\
GR & $3,4,8,9,10,11,12,13,14$ & $1,12,13$ & 12,13 \\
MP & $2,3,4,5,8,9,10,11,12,13,14$ & $1,12,13$ & 12,13 \\
SVC & $1,2,3,5,6,7,8,11,14$ & $1,2,3,4,9,10,11,12,13,14$ & $1,2,3,11,14$ \\
\hline
\end{tabular}

Table 6

Level partitioning Iteration 2

\begin{tabular}{clll}
\hline Enabler & Reachability Set & Antecedent Set & Intersection \\
\hline CCL & $2,3,4,6,7,8,9,10,11,14$ & $2,9,10,11,13,14$ & $2,9,10,11,14$ \\
VHI & $3,6,7,8,10,14$ & $2,3,4,9,10,11,12,13,14$ & $3,10,14$ \\
BM & $3,4,6,7,8,10,14$ & $2,4,9,10,11,12,13$ & 4,10 \\
WI & 6 & $2,3,4,6,7,8,9,10,11,14$ & 6 \\
CRRG & 6,7 & $2,3,4,7,8,9,10,11,14$ & 7 \\
SC & $6,7,8$ & $2,3,4,8,9,10,11,12,13,14$ & 8 \\
DTI & $2,3,4,6,7,8,9,10,11,14$ & $2,9,10,11,12,13$ & $2,9,10,11$ \\
MS & $2,3,4,6,7,8,9,10,11,14$ & $2,3,4,9,10,11,12,13$ & $2,3,4,9,10,11$ \\
DC & $2,3,4,6,7,8,9,10,11,14$ & $2,9,10,11,12,13,14$ & $2,9,10,11,14$ \\
GR & $3,4,8,9,10,11,12,13,14$ & 12,13 & 12,13 \\
MP & $2,3,4,8,9,10,11,12,13,14$ & 12,13 & 12,13 \\
SVC & $2,3,6,7,8,11,14$ & $2,3,4,9,10,11,12,13,14$ & $2,3,11,14$ \\
\hline
\end{tabular}

Table 7

Level partitioning Iteration 3

\begin{tabular}{clll}
\hline Enabler & Reachability Set & Antecedent Set & Intersection \\
\hline CCL & $2,3,4,7,8,9,10,11,14$ & $2,9,10,11,13,14$ & $2,9,10,11,14$ \\
VHI & $3,7,8,10,14$ & $2,3,4,9,10,11,12,13,14$ & $3,10,14$ \\
BM & $3,4,7,8,10,14$ & $2,4,9,10,11,12,13$ & 4,10 \\
CRRG & 7 & $2,3,4,7,8,9,10,11,14$ & 7 \\
SC & 7,8 & $2,3,4,8,9,10,11,12,13,14$ & $2,9,10,11$ \\
DTI & $2,3,4,7,8,9,10,11,14$ & $2,9,10,11,12,13$ & $2,3,4,9,10,11$ \\
MS & $2,3,4,7,8,9,10,11,14$ & $2,3,4,9,10,11,12,13$ & $2,9,10,11,14$ \\
DC & $2,3,4,7,8,9,10,11,14$ & $2,9,10,11,12,13,14$ & 12,13 \\
GR & $3,4,8,9,10,11,12,13,14$ & 12,13 & 12,13 \\
MP & $2,3,4,8,9,10,11,12,13,14$ & 12,13 & $2,3,11,14$ \\
SVC & $2,3,7,8,11,14$ & $2,3,4,9,10,11,12,13,14$ & \\
\hline
\end{tabular}

Table 8

Level partitioning Iteration 4

\begin{tabular}{clll}
\hline Enabler & Reachability Set & \multicolumn{1}{c}{ Antecedent Set } & Intersection \\
\hline CCL & $2,3,4,8,9,10,11,14$ & $2,9,10,11,13,14$ & $2,9,10,11,14$ \\
VHI & $3,8,10,14$ & $2,3,4,9,10,11,12,13,14$ & $3,10,14$ \\
BM & $3,4,8,10,14$ & $2,4,9,10,11,12,13$ & 4,10 \\
SC & 8 & $2,3,4,8,9,10,11,12,13,14$ & 8 \\
DTI & $2,3,4,8,9,10,11,14$ & $2,9,10,11,12,13$ & $2,9,10,11$ \\
MS & $2,3,4,8,9,10,11,14$ & $2,3,4,9,10,11,12,13$ & $2,3,4,9,10,11$ \\
DC & $2,3,4,8,9,10,11,14$ & $2,9,10,11,12,13,14$ & $2,9,10,11,14$ \\
GR & $3,4,8,9,10,11,12,13,14$ & 12,13 & 12,13 \\
MP & $2,3,4,8,9,10,11,12,13,14$ & 12,13 & 12,13 \\
SVC & $2,3,8,11,14$ & $2,3,4,9,10,11,12,13,14$ & $2,3,11,14$ \\
\hline
\end{tabular}


Table 9

Level partitioning Iteration 5

\begin{tabular}{clll}
\hline Enabler & Reachability Set & Antecedent Set & Intersection \\
\hline CCL & $2,3,4,9,10,11,14$ & $2,9,10,11,13,14$ & $2,9,10,11,14$ \\
VHI & $3,10,14$ & $2,3,4,9,10,11,12,13,14$ & $3,10,14$ \\
BM & $3,4,10,14$ & $2,4,9,10,11,12,13$ & 4,10 \\
DTI & $2,3,4,9,10,11,14$ & $2,9,10,11,12,13$ & $2,9,10,11$ \\
MS & $2,3,4,9,10,11,14$ & $2,3,4,9,10,11,12,13$ & $2,3,4,9,10,11$ \\
DC & $2,3,4,9,10,11,14$ & $2,9,10,11,12,13,14$ & $2,9,10,11,14$ \\
GR & $3,4,9,10,11,12,13,14$ & 12,13 & 12,13 \\
MP & $2,3,4,9,10,11,12,13,14$ & 12,13 & 12,13 \\
SVC & $2,3,11,14$ & $2,3,4,9,10,11,12,13,14$ & $2,3,11,14$ \\
\hline
\end{tabular}

Table 10

Level partitioning Iteration 6

\begin{tabular}{clll}
\hline Enabler & Reachability Set & Antecedent Set & Intersection \\
\hline CCL & $2,4,9,10,11$ & $2,9,10,11,13$ & $2,9,10,11$ \\
BM & 4,10 & $2,4,9,10,11,12,13$ & 4,10 \\
DTI & $2,4,9,10,11$ & $2,9,10,11,12,13$ & $2,9,10,11$ \\
MS & $2,4,9,10,11$ & $2,3,4,9,10,11,12,13$ & $2,3,4,9,10,11$ \\
DC & $2,4,9,10,11$ & $2,9,10,11,12,13$ & $2,9,10,11$ \\
GR & $4,9,10,11,12,13$ & 12,13 & 12,13 \\
MP & $2,4,9,10,11,12,13$ & 12,13 & 12,13 \\
\hline
\end{tabular}

Table 11

Level partitioning Iteration 7

\begin{tabular}{cllc}
\hline Enabler & Reachability Set & Antecedent Set & Intersection \\
\hline CCL & $2,9,10,11$ & $2,9,10,11,13$ & $2,9,10,11$ \\
DTI & $2,9,10,11$ & $2,9,10,11,12,13$ & $2,9,10,11$ \\
MS & $2,9,10,11$ & $2,3,9,10,11,12,13$ & $2,3,4,9,10,11$ \\
DC & $2,9,10,11$ & $2,9,10,11,12,13$ & $2,9,10,11$ \\
GR & $9,10,11,12,13$ & 12,13 & 12,13 \\
MP & $2,9,10,11,12,13$ & 12,13 & 12,13 \\
\hline
\end{tabular}

Table 12

Level partitioning Iteration 8

\begin{tabular}{clll}
\hline Enabler & Reachability Set & Antecedent Set & Intersection \\
\hline MS & 10 & $10,12,13$ & 10 \\
GR & $10,12,13$ & 12,13 & 12,13 \\
MP & $10,12,13$ & 12,13 & 12,13 \\
\hline
\end{tabular}

Table 13

Level partitioning Iteration 9

\begin{tabular}{clllc}
\hline Enabler & Reachability Set & Antecedent Set & Intersection & Level \\
\hline GR & 12,13 & 12,13 & 12,13 & IX \\
MP & 12,13 & 12,13 & 12,13 & IX \\
\hline
\end{tabular}

Table 14

Consolidated table of level partitioning of elements

\begin{tabular}{|c|c|c|c|c|c|}
\hline S. No & Enabler & Reachability Set & Antecedent Set & Intersection & Level \\
\hline 1 & CDBE & $1,2,3,5,8,9,10,11,12,13,14$ & $1,2,3,4,5,6,7,8,9,10,11,12,13,14$ & $1,2,3,5,8,9,10,11,12,13,14$ & $\mathrm{I}$ \\
\hline 2 & CCL & $1,2,3,4,5,6,7,8,9,10,11,14$ & $1,2,5,9,10,11,13,14$ & $1,2,5,9,10,11,14$ & VII \\
\hline 3 & VHI & $1,3,5,6,7,8,10,14$ & $1,2,3,4,5,9,10,11,12,13,14$ & $1,3,5,10,14$ & V \\
\hline 4 & $\mathbf{B M}$ & $1,3,4,5,6,7,8,10,14$ & $2,4,9,10,11,12,13$ & 4,10 & VI \\
\hline 5 & PPI & $1,2,3,5,7,8,10$ & $1,2,3,4,5,6,7,8,9,10,11,13,14$ & $1,2,3,5,7,8,10$ & I \\
\hline 6 & WI & $1,5,6$ & $1,2,3,4,6,7,8,9,10,11,14$ & 1,6 & II \\
\hline 7 & CRRG & $1,5,6,7$ & $1,2,3,4,5,7,8,9,10,11,14$ & $1,5,7$ & III \\
\hline 8 & SC & $1,5,6,7,8$ & $1,2,3,4,5,8,9,10,11,12,13,14$ & $1,5,8$ & IV \\
\hline 9 & DTI & $1,2,3,4,5,6,7,8,9,10,11,14$ & $1,2,9,10,11,12,13$ & $1,2,9,10,11$ & VII \\
\hline 10 & MS & $1,2,3,4,5,6,7,8,9,10,11,14$ & $1,2,3,4,5,9,10,11,12,13$ & $1,2,3,4,5,9,10,11$ & VIII \\
\hline 11 & DC & $1,2,3,4,5,6,7,8,9,10,11,14$ & $1,2,9,10,11,12,13,14$ & $1,2,9,10,11,14$ & VII \\
\hline 12 & GR & $3,4,8,9,10,11,12,13,14$ & $1,12,13$ & 12,13 & IX \\
\hline 13 & MP & $2,3,4,5,8,9,10,11,12,13,14$ & $1,12,13$ & 12,13 & IX \\
\hline 14 & SVC & $1,2,3,5,6,7,8,11,14$ & $1,2,3,4,9,10,11,12,13,14$ & $1,2,3,11,14$ & $\mathrm{~V}$ \\
\hline
\end{tabular}


Step 6: MIC MAC Analysis (Cluster of DT Enablers) - The Cross-Impact Matrix Multiplication Applied to the Classification analysis (MIC MAC) analyses the elements based on their driving and dependency powers and groups them into four clusters namely autonomous, dependent, linking and independent factors (Mandal and Deshmukh, 1994) which is built based on multiplication properties of matrices (Sharma et al., 1995). Therefore, these elements are entered respectively based on their DRP and DEP powers as shown in below figure 2. In figure 2, it is observed Autonomous enablers have weak DRP and weak DEP which are completely detached from the system. Here, in this study there are no elements falling under this category. The dependent variables have weak DRP and strong DEP. Enablers 5,6,7,8 are under this cluster. Next is linking enablers, which have strong DRP and strong DEP. Enablers 1,2,3,10,11,14 are under this cluster. The last is independent cluster with strong DRP and weak DEP. Elements 4,9,12,13 are under this cluster.

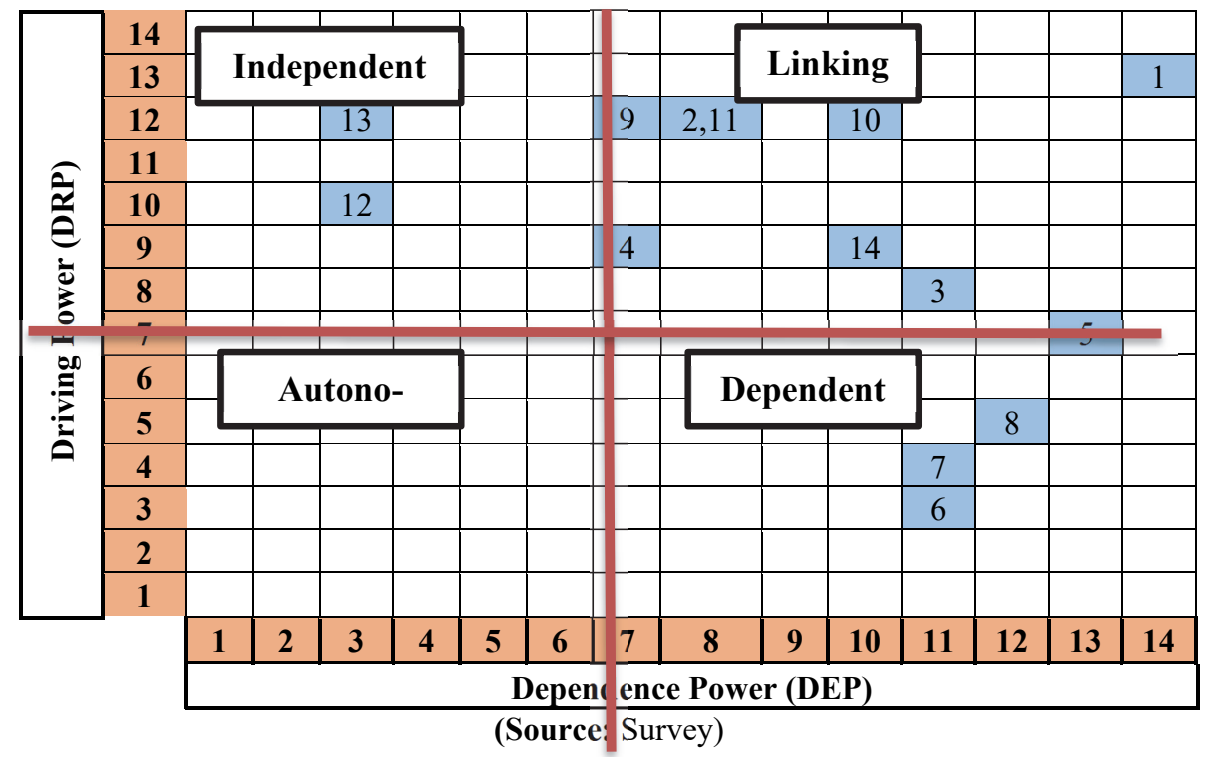

Fig. 2. Classification of DT Enablers

Step 7: Drawing digraph based on the relationship in reachability matrix and remove transitive links - Here the ISM digraph is formulated based on table 4 (RM) and figure 2 (MIC MAC analysis).

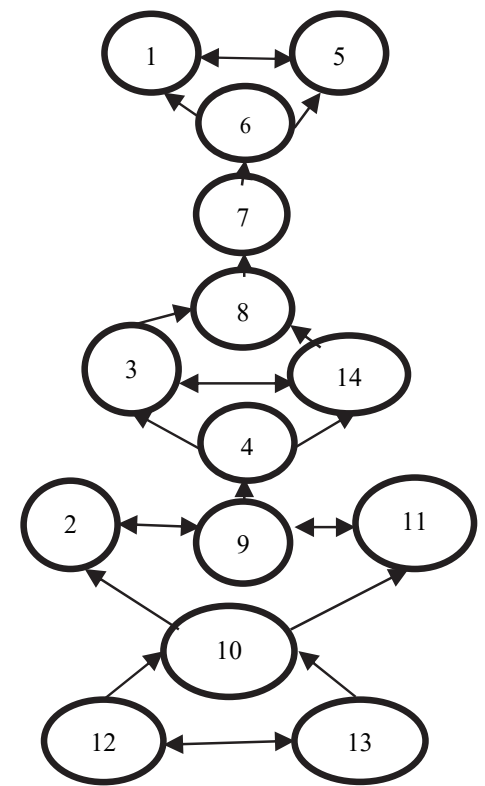

Fig. 3. Diagraph with relationships and after removing transitive links

A digraph is a pictorial representation of the variables and their interdependence in terms of nodes and edges. In the whole process of model development, the top-level elements are placed in the top level of digraph and second-level elements in the second level and the process continues till all the elements occupy their respective levels in the digraph. Thus, the final digraph is represented in Fig. 3 subsequently removing the transitive links and with nodes and arrows, which is further converted into 
the ISM model as in Fig. 4. The single arrows represent the one-way relationship and double arrows the two-way relationship among respective enablers.

Step 8: Transform digraph into the ISM model by substituting elements nodes with statements - As explained in the previous step 7, the below figure 4 represents the proposed ISM based model showing relationships and interdependence among enablers of DT. This step replaces the variable nodes with the related statements.

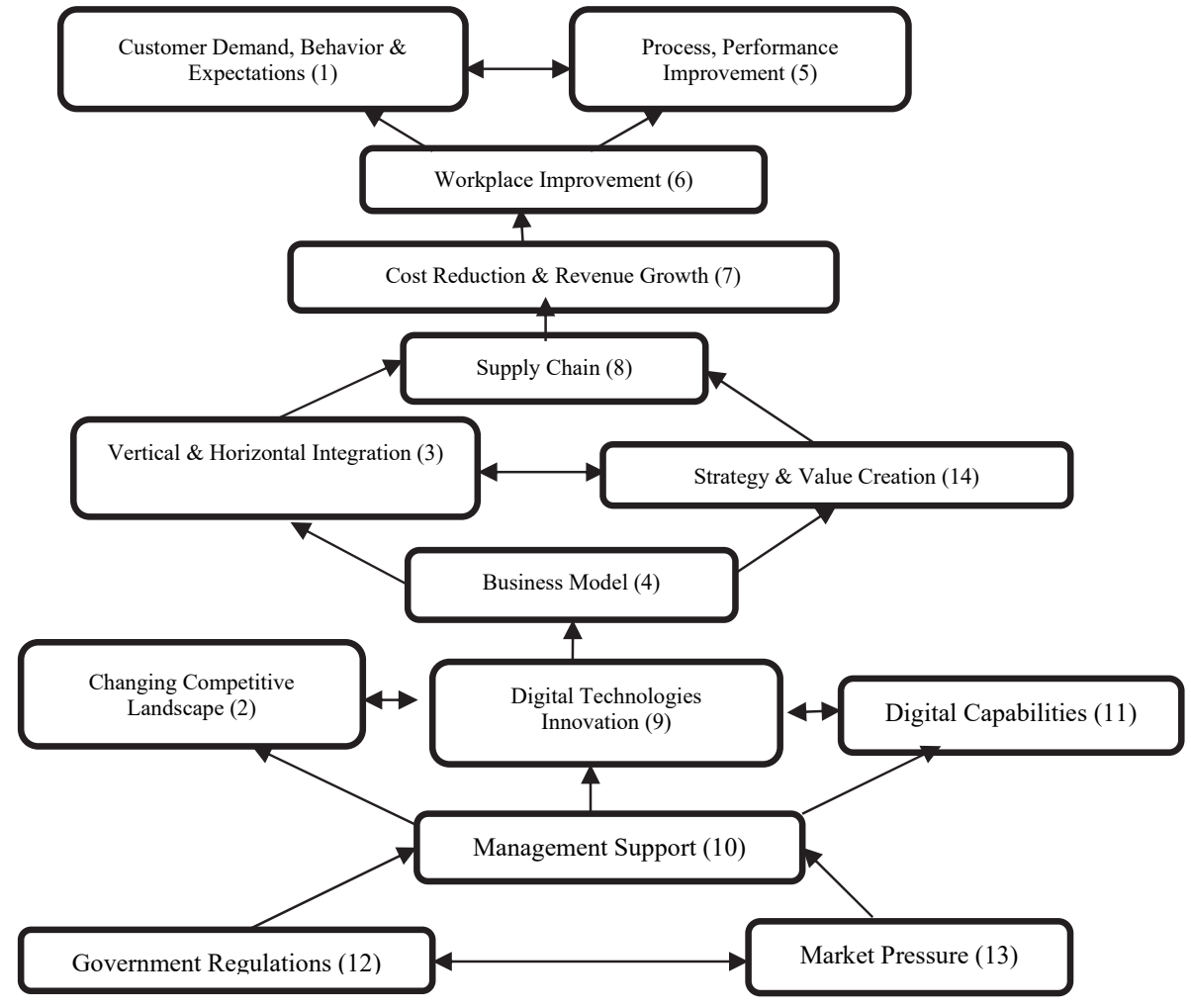

Fig. 4. Proposed ISM based model of DT Enablers

\section{Findings, Discussion, and Managerial Implications}

This study has attempted to identify the possible enabling factors that are driving various organizations towards digital transformation adoption. The extant literature review has identified fourteen enablers for DT adoption. To answer the research questions on the levels occupied by each identified factor their interrelationships and respective driving and dependence power, these enabling factors were structurally modeled using ISM methodology. All the drivers together formed the ISM model in 9 levels based on their interrelationships, driving, and dependence powers as explained in MIC MAC analysis. Among all the drivers, Government regulations and market pressure have explained a strong driving power and weak dependence power occupying the bottom level in the ISM model. Therefore, these enablers serve the organizations as crucial driving factors for DT adoption. This infers both these variables will initiate the industries to adopt DT and takes a different approach to effectively invoke the DT strategies improving the internal process, business systems and social media marketing. Consumer demand, behavior, and expectations and process, performance improvement occupy the uppermost level in the model indicating the poor driving and robust dependency power. However, these factors were highly influenced by other organizational practices. The elements in the lower level are highly influencing the other elements above them in the hierarchy. In Fig. 2 of MIC MAC analysis, there were no autonomous elements that indicate no elements were disconnected from the system. Process and performance improvement, workplace improvement, cost reduction, and revenue growth and supply chain found to be more dependent factors, which need more support from the management. However, customer demand, behavior, and expectations; changing competitive landscape; vertical and horizontal integration; management support; digital capabilities and strategy and value creation fall under linking variables. The linking and dependent variables have strong driving power towards DT. The developed model demonstrates industries to leverage on various dimensions to emphasize on transforming their business process. It provides a deep insight for the managers and consumers on what critical factors they may consider in dealing with dimensions of digitalizing their business transactions and also while considering new business models in the adoption of DT. Further, it may provide implications to the firms to improve competence by supplementing other operational factors and advance in innovations by intensely reducing their business costs. Moreover, good knowledge on digital transformational aspects drive towards a better utilization of social networking platforms and assists in acquiring new and profitable business by reaching the targeted customers. This also helps the firms to develop new marketing strategies in the present 
digital era. Further it helps organizations how to overcome the cutting-edge competition and excel in social network marketing.

\section{Conclusion and scope for future research}

In recent years, DT has been dramatically emerging in the market with significant changes in the whole business process. While most of the organizations fail to adopt such strategies, the rest of the firms are still moving at a very slow pace with a dilemma on which dimension they need to focus on. In the meantime, big organizations are rapidly entering the market with the advantage of digital innovations and grabbing the large market share. As DT adoption depends on various factors, this study throws a deep insight especially for small and medium-sized organizations on choosing the most important driving factors and the dimensions on which they need to emphasize transforming their business process. Such clarity will help them in improving competence by supplementing other production factors and develop innovation by intensely reducing the business cost. As this model is extensively developed based on a logical and systematic approach by understanding the driving and dependence power of each identified factor, it can further be validated among various industries to demonstrate specific and appropriate findings applicable for each of them. As this study considered the common driving factors applicable to every sector, sometimes few factors may not apply to specific industry. Therefore, further researchers can extend this model by considering more relevant factors. However, considering too many factors will make it complicated in developing the ISM model. Also, any other studies can consider sub-factors and prioritize them by using the analytical hierarchy process (AHP) across various industries as a multi-criterion decision-making process. The above conceptual model is developed on a logical basis but is not statistically validated. So further studies can attempt to validate the model by using a static tool like structural equation modeling (SEM) or may investigate the dynamic behavior of the model using system dynamics.

\section{References}

Berghaus, S., \& Back, A. (2017). Disentangling the Fuzzy Front End of Digital Transformation: Activities and Approaches. In ICIS 2017 Proceedings, 1-17.

Berman, S.J. (2012). Digital transformation: Opportunities to create new business models. Strategy \& Leadership, 40(2), 1624.

Berman, S.J., \& Marshall, A. (2014). The next digital transformation: From an individual centered to an everyone-to-everyone economy. Strategy \& Leadership, 42(5), 9-17.

Bilgeri, D., Wortmann, F., \& Fleisch, E. (2017). How digital transformation affects large manufacturing companies' organization. In ICIS 2017 Proceedings: 1-9.

Ezeokoli, F.O., Okolie, K.C., \& Okoye, P.U. (2016). Digital transformation in the Nigeria construction industry: The professionals' view. World Journal of Computer Application and Technology, 4(3), 23-30.

Fichman, R.G., Dos Santos, B.L., \& Zheng, Z. (2014). Digital innovation as a fundamental and powerful concept in the information systems Ccurriculum. MIS Quarterly, 38(2), 329-353.

Fitzgerald, M., Kruschwitz, N., Bonnet, D., \& Welch, M. (2013). Embracing Digital Technology: A New Strategic Imperative. MIT Sloan Management Review, Research Report.

Haffke, I., Kalgovas, B., \& Benlian, A. (2017). The transformative role of bimodal IT in an era of digital business. In 50th Hawaii International Conference on System Sciences, 5460-5469.

Hartl, E., \& Hess, T. (2017). The Role of Cultural Values for Digital Transformation: Insights from a Delphi Study. In AMCIS 2017 Proceedings, 1-10. Retrieved from http://aisel.aisnet.org/cgi/viewcontent.cgi?article=1369\&context=amcis 2017

Isaksson, V., \& Hylving, L. (2017). The Effect of Anarchistic Actions in Digital Product Innovation Networks: The Case of Over the Air. Software Updates. In 50th Hawaii International Conference on System Sciences, 5763-5772. Retrieved from http://hl-128-171-5722.library.manoa.hawaii.edu/handle/10125/41858

Kane, G., Palmer, D., Phillips, A., Kiron, D., \& Buckley, N. (2015). Strategy, not Technology, Drives Digital Transformation. MIT Sloan Management Review and Deloitte University Press, vol. 14.

Kane, G. C., Palmer, D., Phillips, A. N., \& Kiron, D. (2015). Is your business ready for a digital future?. MIT Sloan Management Review, 56(4), 37.

Kannan P.K. \& Hongshuang Alice Li. (2017). Digital marketing: A framework, review and research agenda. International Journal of Research in Marketing, 34, 22-45.

Karen, O., Jon, I., \& Bendik, B. (2018). Digital transformation: drivers' success factors and implications. $12^{\text {th }}$ Mediterranean Conference on Information Systems (MCIS). Corfu, Greece 2018 Proceedings, pp. 1-15

Kirsten, L, N., Sven, P., \& Kristin, V. (2018). Drivers of Digital Transformation in Manufacturing. Proceedings of $51^{\text {st }}$ Hawali Inernational Conference on System Sciences, pp. 3926-35.

Malcolm, H. (2015). Cyber Monday Clocks record sales as mobile sales surge. USA Today Dec 2. Accessed from https:/www.usatoday.com/story/money/2015/12/01/cyber-monday-sales-results/76602534/

Mandal, A., \& Deshmukh, S. (1994). Vendor selection using interpretive structural modeling (ISM). International Journal of Operations and Production Management, 14(6), 52-59.

Mihailescu, M., Mihailescu, D., \& Schultze, U. (2015). The Generative Mechanisms of Healthcare Digitalization. In Icis conference, pp. 1-12. 
Morakanyane, R., Grace, A., \& O’Reilly, P. (2017). Conceptualizing digital transformation in business organizations: A systematic review of literature. In: Proceedings of the 30th Bled E-Conference, Bled: Slovenia, pp. 427-443.

Nwankpa, J.K., \& Roumani, Y. (2016). IT capability and digital transformation: A firm performance perspective. In ICIS 2016 Proceedings, pp. 1-16.

Okoli, C., \& Pawlowski, S.D. (2004). The Delphi method as a research tool: An example, design considerations and applications. Information \& Management, 42(1), 15-29.

Remane, G., Hildebrandt, B., Hanelt, A., \& Kolbe, L.M. (2016). Discovering New Digital Business Model Types: A Study of Technology Startups. In AMCIS 2016 Proceedings. pp. 1-10. Retrieved from http://aisel.aisnet.org/pacis2016/289

Sage, A.P. (1977). Interpretive structural modeling: Methodology for large scale systems. New York, NY: McGraw-Hill

Schmidt, J., Drews, P., \& Schirmer, I., (2017). Digitalization of the Banking Industry: A Multiple Stakeholder Analysis on Strategic Alignment. In AMCIS 2017 Proceedings. pp. 1-10.

Sharma, H.D., Gupta, A.D., \& Sushil. (1995). The objectives of waste management in India: A future inquiry. Technological Forecasting and Social Change, 48, 285-309.

Skinner, R., Nelson, R.R., Chin, W.W., \& Land, L. (2015). The Delphi Method Research Strategy in Studies of Information Systems. Communications of the Association for Information System, 37(1), 2.

Skog, D.A., Wimelius, H., \& Sandberg, J. (2018). Digital disruption. Business \& Information Systems Engineering, 60(5), 431-437.

Warfield, J.W. (1974). Developing interconnected matrices in structural modeling. IEEE transcript on systems. Men and Cybernetics, 4(1), 51-81.

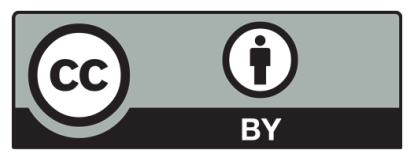

(C) 2020 by the authors; licensee Growing Science, Canada. This is an open access article distributed under the terms and conditions of the Creative Commons Attribution (CC-BY) license (http://creativecommons.org/licenses/by/4.0/). 